\title{
Review: 3 to 7 months of prednisone is more effective than 2 months in children with steroid responsive nephrotic syndrome
}

\author{
Hodson EM, Knight JF, Willis NS, et al. Corticosteroid therapy in nephrotic syndrome: a meta-analysis of randomised \\ controlled trials. Arch Dis Child 2000 Jul;83:45-51.
QUESTION: In children with steroid responsive nephrotic syndrome (SRNS), what is the optimal corticosteroid regimen?

\section{Data sources}

Studies were identified by searching Medline (1966 to July 1998), EMBASE/Excerpta Medica (1988 to July 1998), and the Cochrane Controlled Trials Register (1998); scanning reference lists of relevant articles, nephrology textbooks, and proceedings of scientific meetings; and contacting investigators.

\section{Study selection}

2 reviewers independently selected studies if they were randomised or quasirandomised controlled trials, involved children who were 3 months to 18 years of age and had initial or subsequent episodes of SRNS, compared different regimens of prednisone or other corticosteroid agents, and reported $\geqslant 6$ months of follow up data.

\section{Data extraction}

2 reviewers independently extracted data on setting, publication year, number of patients in each group, dose and duration of treatments, study methods, and outcome (the primary outcome was the prevention of relapse). 2 reviewers assessed the quality of study methods.

\section{Main results}

12 studies (868 children) met the selection criteria. In children with a first episode of SRNS, 5 studies compared 3 to 7 months of prednisone treatment (daily for 1 to $2 \mathrm{mo}$ and on alternate days for 1.5 to $6 \mathrm{mo}$ ) with 2 months of standard treatment (prednisone, $60 \mathrm{mg} / \mathrm{m}^{2}$ daily for 4 weeks followed by $40 \mathrm{mg} / \mathrm{m}^{2}$ on 3 of 7 days). At 6 and 12 to 24 months, relapses were fewer for children who received 3 to 7 months of prednisone than for those who received standard treatment (table). Serious adverse events and number of infections did not differ between groups. In children with relapsing SRNS, 1 study showed fewer relapses for children who received daily therapy than for those who received intermittent therapy while they were on treatment (weighted relative

Wales 2124, Australia

Fax +61298453432

Relapse rates for prednisone for 3 to 7 months $v 2$ months in children with the steroid responsive nephrotic syndrome*

\begin{tabular}{|c|c|c|c|c|c|}
\hline \multirow[b]{2}{*}{ Follow up } & \multirow{2}{*}{$\begin{array}{l}\text { Number of } \\
\text { studies }\end{array}$} & \multicolumn{2}{|c|}{ Weighted event rates } & \multirow[b]{2}{*}{$\operatorname{RRR}(95 \% \mathrm{Cl})$} & \multirow[b]{2}{*}{ NNT (Cl) } \\
\hline & & 3 to 7 months & 2 months & & \\
\hline 6 months & 4 & $\dagger$ & $\dagger$ & $41 \%$ (24 to 54$)$ & $4(2$ to 6$)$ \\
\hline 12 to 24 months & 5 & $48 \%$ & $68 \%$ & $27 \%(11$ to 40$)$ & 5 (3 to 10$)$ \\
\hline
\end{tabular}

*Abbreviations defined in glossary; weighted event rates calculated from data in article. †Data not reported. risk reduction [RRR] 80\%, 95\% CI 18\% to 95\%), but no difference existed by 9 months (weighted RRR 0\%, CI $-12 \%$ to $11 \%$ ). 1 study showed that deflazacort led to fewer relapses than did prednisone at 1 year (weighted RRR $56 \%$, CI $22 \%$ to $75 \%$ ). No difference in relapse rates was seen between alternate day prednisone and intermittent prednisone (1 study), intravenous and oral steroids ( 1 study), and single and divided doses of prednisolone (1 study).

\section{Conclusion}

In children with a first episode of steroid responsive nephrotic syndrome, prolonged treatment with alternate day prednisone for 3 to 7 months leads to fewer relapses than standard 2 month treatment.

\section{COMMENTARY}

Most clinicians accept that when the first episode of nephrotic syndrome responds to prednisone, a total of 4 to 6 weeks of daily treatment is required. ${ }^{1}$ A cushingoid face or behavioural side effects in young children may be practical limiting factors that make 4 weeks long enough for some parents rather than the slightly more desirable 6 weeks of treatment. This meta-analysis by Hodson et al challenges the common practice of then changing to alternate day prednisone and phasing it out after another 4 to 6 weeks. A lower relapse rate seems possible and certainly desirable because those who relapse often go on to have many relapses, which increases the risk for infection, thrombosis, and side effects of second line drugs.

Children usually tolerate prolonged alternate day prednisone well, and more often it is the repeated courses of daily prednisone that ultimately contribute to serious steroid toxicity. Thus, many paediatric nephrologists will probably accept the recommendations of this review for children with their first episode of nephrotic syndrome. Further trials should be done to confirm the possible advantage of deflazacort over prednisone in children with frequently relapsing or steroid dependent nephrotic syndrome. ${ }^{2}$

Brian T Steele, MD McMaster University Hamilton, Ontario, Canada

1 Bargman JM. Management of minimal lesion glomerulonephritis: evidence-based recommendations. Kidney Int Suppl 1999;70:S3-16.

2 Broyer M, Terzi F, Lehnert A, et al. A controlled study of deflazacort in the treatment of idiopathic nephrotic syndrome. Pediatr Nephrol 1997;11:418-22. 